University of Nebraska - Lincoln

DigitalCommons@University of Nebraska - Lincoln

\title{
Characterization of Electrochemically Active Bacteria Utilizing a High-Throughput Voltage-Based Screening Assay
}

\author{
Justin C. Biffinger \\ US Naval Research Laboratory, justin.biffinger@nrl.navy.mil \\ Meghann Ribbens \\ University of Southern California \\ Bradley Ringeisen \\ US Naval Research Laboratory \\ Jeremy Pietron \\ US Naval Research Laboratory \\ Steven Finkel \\ University of Southern California \\ See next page for additional authors
}

Follow this and additional works at: https://digitalcommons.unl.edu/usnavyresearch

Part of the Operations Research, Systems Engineering and Industrial Engineering Commons

\footnotetext{
Biffinger, Justin C.; Ribbens, Meghann; Ringeisen, Bradley; Pietron, Jeremy; Finkel, Steven; and Nealson, Kenneth, "Characterization of Electrochemically Active Bacteria Utilizing a High-Throughput VoltageBased Screening Assay" (2009). U.S. Navy Research. 11.

https://digitalcommons.unl.edu/usnavyresearch/11
}

This Article is brought to you for free and open access by the U.S. Department of Defense at DigitalCommons@University of Nebraska - Lincoln. It has been accepted for inclusion in U.S. Navy Research by an authorized administrator of DigitalCommons@University of Nebraska - Lincoln. 
Authors

Justin C. Biffinger, Meghann Ribbens, Bradley Ringeisen, Jeremy Pietron, Steven Finkel, and Kenneth Nealson 


\title{
Characterization of Electrochemically Active Bacteria Utilizing a High-Throughput Voltage-Based Screening Assay
}

\author{
Justin Biffinger, ${ }^{1}$ Meghann Ribbens, ${ }^{2}$ Bradley Ringeisen, ${ }^{1}$ Jeremy Pietron, ${ }^{1}$ \\ Steven Finkel, ${ }^{2}$ Kenneth Nealson ${ }^{3}$ \\ ${ }^{I}$ Chemistry Division, US Naval Research Laboratory, 4555 Overlook Avenue, SW, \\ Washington, District of Columbia 20375; telephone: 202-767-2398; \\ fax: 202-404-8119; e-mail: justin.biffinger@nrl.navy.mil \\ ${ }^{2}$ Molecular and Computational Biology Program, Department of Biological Sciences, \\ University of Southern California, Los Angeles, California \\ ${ }^{3}$ Department of Earth Sciences, University of Southern California, Los Angeles, California \\ Received 19 June 2008; revision received 22 July 2008; accepted 24 July 2008 \\ Published online 5 August 2008 in Wiley InterScience (www.interscience.wiley.com). DOI 10.1002/bit.22072
}

\begin{abstract}
Metal reduction assays are traditionally used to select and characterize electrochemically active bacteria (EAB) for use in microbial fuel cells (MFCs). However, correlating the ability of a microbe to generate current from an MFC to the reduction of metal oxides has not been definitively established in the literature. As these metal reduction assays may not be generally reliable, here we describe a four- to nine-well prototype high throughput voltage-based screening assay (VBSA) designed using MFC engineering principles and a universal cathode. Bacterial growth curves for Shewanella oneidensis strains DSP10 and MR-1 were generated directly from changes in open circuit voltage and current with five percent deviation calculated between each well. These growth curves exhibited a strong correlation with literature doubling times for Shewanella indicating that the VBSA can be used to monitor distinct fundamental properties of EAB life cycles. In addition, eight different organic electron donors (acetate, lactate, citrate, fructose, glucose, sucrose, soluble starch, and agar) were tested with S. oneidensis MR-1 in anode chambers exposed to air. Under oxygen exposure, we found that current was generated in direct response to additions of acetate, lactate, and glucose.
\end{abstract}

Biotechnol. Bioeng. 2009;102: 436-444.

(C) 2008 Wiley Periodicals, Inc.

KEYWORDS: microbial fuel cell; high-throughput screening; Shewanella; metal reduction; voltage

Correspondence to: J. Biffinger

Contract grant sponsor: Office of Naval Research (NRL 6.2 Program Element) Contract grant number: $62123 \mathrm{~N}$

Contract grant sponsor: Air Force Office of Scientific Research (MURI Program)

Contract grant number: FA9550-06-1-0292

\section{Introduction}

The discovery of microbes that couple metal reduction to produce energy for anaerobic growth (DiChristina et al., 1988; Lovley and Phillips, 1988; Myers and Nealson, 1988) has generated a significant amount of research on the identification and manipulation of metal reducing microbes for applications ranging from bioremediation of heavy metals (Lovley and Coates, 1997) to harvesting electricity from biomass (Logan and Regan, 2006). Microbes capable of metal reduction within environmental samples are commonly isolated and identified based on their ability to reduce certain transition metal or actinide electron acceptors (iron and manganese oxides, technetium, uranium) by either colorimetric assays (Lovley and Phillips, 1987) or plating on agar indicator supports (Ganesh et al., 1997; Payne and DiChristina, 2006; Taratus et al., 2000). For example, metal reduction assays were used to identify electrochemically active bacteria (EAB) obtained from the anode of a microbial fuel cell (MFC) submerged in sediment from Boston Harbor, MA. (Bond et al., 2002). Reduction of solid metal oxides by $\mathrm{EAB}$ is generally considered to be concomitant with electricity production from MFCs. However, the mechanisms of extracellular electron transfer from bacteria to carbon electrodes and insoluble metal oxides are still illdefined (Chang et al., 2006; Stams et al., 2006). Specifically, Shewanella (one of the two families of bacteria frequently used in pure culture MFCs) express multiple pathways for electron transfer to graphite electrodes and manganese/iron oxides (Bretschger et al., 2007).

In contrast to past results, recent experiments suggest that the connection between current output from MFCs and metal oxide reduction for unidentified $\mathrm{EAB}$ in the environment is tenuous. The first significant disconnect between 
metal reduction and electricity output from MFCs was recently observed with Pelobacter carbinolicus (Richter et al., 2007). Pelobacter are of interest for MFCs because of their phylogenetic relationship to the other major bacterial family used in MFC research, Geobacteracae (Lovley et al., 1997). It was observed that Pelobacter was capable of reducing Fe(III) oxides but did not generate current in a MFC. Thus, the expression of multiple pathways for electron transfer to different electron donors and the lack of current generation from a MFC by $P$. carbinolicus brings into question how many other species of EAB can reduce metal oxides yet may not be able to deliver electrons to a carbon electrode or vice versa.

To date, little has been published on rapidly screening electrochemically active biological species for use as energy harvesters or biosensors. Routinely, multiple MFC experiments are performed in serial (slow due to time between experiments) or in parallel by running multiple larger scale MFCs at the same time. Since running a single full scale MFC requires significant space and materials, then a single device with multiple wells would be more efficient. Rapid screening methods are desirable, as the best candidates for a given MFC application need to be identified quickly and accurately. High-throughput screening (HTS) continues to be primarily focused on the automation, detection, and miniaturization of assay technology (Burbaum and Sigal, 1997; Sundberg, 2000). Bacterial metabolism can be significantly influenced by environmental stressors (Storz and HenggeAronis, 2000), and correlating all of the potential variables and mutations with current output would require a standardization between research groups in the MFC field for every bacterial sample with a defined power output.

Several strategies have been used for HTS of both whole cell or catalytic activity from enzymes and function (DiazMochon et al., 2007). After the introduction of the 96-well microtiter plate and spectrophotometric plate readers, a clear distinction arose between HTS and traditional laboratory assays. Some of these differences are provided in Table I and were described in detail within a review by Inglese et al. (2007). A noteworthy difference between laboratory assays and HTS are a significantly reduced sample size for HTS and a simple protocol. There are no HTS assays in the literature that monitor biological function as it relates directly to current generating ability or power output.

There has been some interesting work on assay technology to identify and manipulate bacteria for bioremediation research. DiChristina and coworkers have published a rapid screening routine for identifying $\mathrm{Mn}$ (IV) (Burnes et al.,
1998), Tc(VII) (Payne and DiChristina, 2006), and Se(IV) (Taratus et al., 2000) reduction by Shewanella mutants using indicator plate assays. However, changes in thermal growth conditions cannot be varied across plate assays and only 1012 colonies can be analyzed at one time by digitally imaging each plate separately. Miniature biological reactors have been developed as a way to increase the number of growth and metabolic variables within a single device (Harms et al., 2005; Maharbiz et al., 2004). For Shewanella specifically, a high-throughput mini-bioreactor was fabricated for the rapid screening of growth conditions (Tang et al., 2006). Their multi-component mini-bioreactor (10 $\mathrm{mL}$ volume) generated 24 different growth conditions for S. oneidensis by changing the $\mathrm{pH}, \mathrm{O}_{2} / \mathrm{CO}_{2}$ content, and temperature in each well but relied on external analysis of growth rates and metal reduction.

Researchers studying hydrogen/oxygen fuel cell catalysts have developed HTS methods for screening potential catalysts for increased activity (current output) and stability (Smotkin et al., 2006). Unlike hydrogen/oxygen fuel cells, biological fuel cells do not require stringent catalyst preparation; thus making it possible to create a biological reactor with a common cathode and catholyte directly from a basic batch reactor design. A HTS assay for EAB will need to account for the bacterial conditioning of the anode surface and gradual bacterial biofilm formation (Kim et al., 1999, 2002); a process that can take several weeks.

The device described in this work is an operational prototype of an HTS assay that uses real time voltage detection instead of metal reduction as an indicator for potential microbial power output from MFCs. The design is based on general MFC principles using a ferricyanide catholyte for each assay. Shewanella oneidensis strains MR-1 or DSP10 were used for bacterial growth studies as well as power output from various carbon fuels. The data collected in this platform resulted in the efficient determination of energy harvesting potential compared to using large scale individual MFCs and enabled multiple nutrients to be screened simultaneously for current and power output from Shewanella.

\section{Materials and Methods}

Stock solutions of D-glucose $(1.0 \mathrm{M})$, D-fructose $(0.5 \mathrm{M})$ were filter sterilized $(0.2 \mu \mathrm{m}$ cellulose nitrate filter). Stock solutions of sodium lactate (1.95 M adjusted to $\mathrm{pH} 7)$, sodium acetate $(1.95 \mathrm{M}), 1 \%$ agar, sucrose, $2 \%$ starch,

Table I. Parameters for distinguishing between laboratory assays and HTS assays.

\begin{tabular}{lll}
\hline Parameter & \multicolumn{1}{c}{ Laboratory } & \multicolumn{1}{c}{ HTS } \\
\hline Protocol & Can be complexed with numerous steps & Less than 10 steps, simple, addition only \\
Assay volume & $0.1-1 \mathrm{~mL}$ & $<1-400 \mu \mathrm{L}$ \\
Reagents & Quantity often limited, different batches & Single batch, stable over long time \\
Variables & Time, substrate, compound & Compound (mg quantity), compound concentration \\
Assay container & Tube, slide, microtiter plate, Petri dish, cuvette, animal & Microtiter plate \\
Time & Milliseconds-months & Minutes-hours \\
Output & Plate reader, size separation, radioactivity & Plate reader (fluorescence, luminescence, absorbance) \\
\hline
\end{tabular}


sodium citrate $(0.5 \mathrm{M})$ were sterilized by autoclave $(13 \mathrm{~min}$, $121^{\circ} \mathrm{C}$ ). All VBSA experiments were performed a minimum of three times and conclusions were drawn from similar trends in each experiment.

\section{Cell Culture Conditions}

The DSP10 and MR-1 strains of S. oneidensis were obtained from the Nealson lab strain collection. Both strains were inoculated from $-80^{\circ} \mathrm{C}$ frozen stock cultures, and grown in $50 \mathrm{~mL}$ of Luria-Bertani (LB) broth with gentle shaking (100 $\mathrm{rpm})$ at $25^{\circ} \mathrm{C}$ in $125 \mathrm{~mL}$ flasks aerobically.

\section{Dimensions and Fabrication of Pipet Microbial Fuel Cell}

Graphite felt (GF, Electrosynthesis Company, Lancaster, $\mathrm{NY}, 15 \mathrm{mg}$ ) woven with a titanium wire was pressed into the bottom half of a separated $1 \mathrm{~mL}$ pipetter tip (Fisher Scientific, Pittsburgh, PA). This chamber was then attached to a pre-treated Nafion-117 membrane with 5 min epoxy (Devcon, Danvers, MA). The upper (anode) chamber was attached to the opposite side of the membrane with $5 \mathrm{~min}$ epoxy and $25 \mathrm{mg}$ of graphite felt (woven with a titanium wire) was pressed inside. The two chambers were attached permanently with marine epoxy (Loctite, Avon, $\mathrm{OH}$ ) on the outside of the device (Fig. 1). A stationary phase culture $(500 \mu \mathrm{L})$ of $S$. oneidensis DSP10 $\left(1 \times 10^{8} \mathrm{CFU} / \mathrm{mL}\right)$ was added to the anode chamber serving as the anolyte. Three pipet MFCs were placed in a stirred $50 \mathrm{mM}$ potassium ferricyanide dissolved in $100 \mathrm{mM} \mathrm{pH} 7$ sodium phosphate buffer as a standard catholyte. The cathodes from each independent fuel cell were connected in parallel with titanium wire.

\section{Dimensions and Fabrication of the Four- to Nine-Well Voltage-Based Screening Assays (VBSAs)}

VBSAs containing four to nine wells (Fig. 3) were constructed for these experiments. The upper $4.3 \mathrm{~cm} \times 4.3 \mathrm{~cm}$ VBSA frame was formed from a $1.3 \mathrm{~cm}$ thick polysulfone polymer sheet (Trident Engineering Plastics, Bristol, PA). The frame was fabricated from polysulfone because of its resistance to typical sterilization temperatures $\left(121-125^{\circ} \mathrm{C}\right)$ and machinability. The diameter of each well was $0.8 \mathrm{~cm}$. A second $0.5 \mathrm{~cm}$ thick polysulfone polymer sheet was cut to the same size frame as above with mirroring $0.5 \mathrm{~cm}$ diameter holes to aid in supporting the separator to the main array. The separator between the polysulfone sheets was a pretreated Nafion ${ }^{\circledR}$ - 117 membrane (deionized (DI) water, 3\% hydrogen peroxide solution, $1 \mathrm{M}$ sulfuric acid, and DI water at $70^{\circ} \mathrm{C}$ for $1 \mathrm{~h}$ each). The Nafion-117 membrane was then hot pressed ( $5 \mathrm{~min}, 100 \mathrm{psi}, 150^{\circ} \mathrm{C}$ ) with Toray Carbon Paper (E-TEK, TGPH-090) connected with a titanium wire. The anodes were fabricated from a titanium metal sheet (active electrode area, $0.3 \mathrm{~cm} \times 0.3 \mathrm{~cm}$ ) coated with a conductive carbon ink. The carbon ink contained $30 \mathrm{mg}$ carbon black, $300 \mu \mathrm{L}$ 2-propanol, $300 \mu \mathrm{L}$ 5\% Nafion Solution in water, and $2 \mathrm{~mL}$ of de-ionized water. The ink was sonicated for $30 \mathrm{~min}$ prior to application (drop-cast method) to the bottom half of one side of etched ( $1 \mathrm{M}$ $\mathrm{HCl}, 80^{\circ} \mathrm{C}, 5 \mathrm{~min}$ ) titanium foil (Goodfellow Cambridge Limited, Huntingdon, England) cut into an "L" shape. Each titanium anode was placed in a chamber. The entire device was then assembled immediately with zinc plated screws and sterilized in an autoclave at $121^{\circ} \mathrm{C}$ for $13 \mathrm{~min}$. The fully assembled VBSA was autoclaved as one piece including the titanium electrodes in each anode chamber to limit bacterial contamination. A conditioning period $(<24 \mathrm{~h})$ was required for the wetting of the membrane electrode assembly in the VBSA device because it was hot pressed to carbon paper and autoclaved prior to use which resulted in the membrane drying.

The catholyte for each experiment was a filter sterilized $50 \mathrm{mM}$ potassium ferricyanide solution in $100 \mathrm{mM}$ phosphate buffer ( $\mathrm{pH}$ 7.0). Due to the well-defined electrochemical properties of potassium ferricyanide and its presence in excess concentration, changes in overall cell voltage and current output will be dictated by each anode. There was no detectible cross-over of the ferricyanide into the anode chamber throughout the duration of the experiment. Marine epoxy (Loctite) was coated around the junction between the polysulfone sheets and Nafion-117 to protect the chambers from ferricyanide seepage and over the zinc plated screws exposed to the ferricyanide catholyte. The container for the VBSA (Fig. 3C) was sterilized with 10\% bleach and UV irradiation in the biosafety hood prior to use. The VBSA was placed into the catholyte solution to complete the device. The potential of the cathode was monitored versus $\mathrm{Ag} / \mathrm{AgCl}$ (Analytical Sensors, Inc., Sugarland, TX) using an ORION 330 electrochemical apparatus (Thermo Electron Corp., Waltham, MA). All sterile manipulations were performed in a biosafety flow hood.

\section{Data Acquisition}

The voltages at open circuit or across a $100 \mathrm{k} \Omega$ resistor (in a custom nine-resistor bank made for simultaneous measurements) were recorded with a personal data acquisition device (I/O tech, personal daq/54) every $2 \mathrm{~min}$. Ohm's law was used to convert voltage to current and to generate polarization curves. The polarization curves for each pipet fuel cell were recorded by changing the external resistance of each fuel cell independently.

\section{Monitoring the Growth of $\boldsymbol{S}$. oneidensis With Voltage and Current}

In a five-well VBSA, $300 \mu \mathrm{L}$ of sterile LB was inoculated with $100 \mu \mathrm{L}$ of a culture containing $1 \times 10^{8} \mathrm{CFU} / \mathrm{mL}$ S. oneidensis MR-1 or DSP10 in LB. The growth of the cells was monitored with time using the voltage output from each well versus the ferricyanide cathode system. A $100 \mathrm{k} \Omega$ 
resistor was used during experiments for the determination of current output for either growth or carbon source utilization. Growth experiments following current output contained the redox mediator 9,10-anthraquinone-2,6 disulfonic acid (AQDS, $5 \mathrm{mM}$ ) to eliminate changes in current derived from differential mediator secretion and biofilm formation.

\section{Results and Discussion}

\section{Pipet Microbial Fuel Cells}

To date, a multi-anode/common cathode MFC has not been reported in the literature. The initial design concept for the VBSA was brought to practice by simply modifying $1 \mathrm{~mL}$ pipetter tips (Fig. 1). Three pipet MFCs were placed in a standard potassium ferricyanide catholyte. The ferricyanide concentration was in excess so that large changes in localized concentration would not affect the working potential of the cathode. Sodium lactate was added periodically to the anode chambers containing S. oneidensis DSP10 to concentrations of 20-30 mM over the period of 4-6 days during the experiment.

The voltages across an external resistor $(8,600$ or $4,700 \Omega)$ or at open circuit (OCV) were recorded with time from three pipet MFCs (Fig. 2A). There was a negligible difference in voltage output between MFCs 1 and 3 under identical conditions, while MFC 2 exhibited a slight variation from the other two. In general, the use of GF in these designs is limited because the connection between the titanium wire and GF deteriorates upon wetting. Therefore, titaniumtitanium connections were used for the anodes in the subsequent VBSA design, resulting in a substantial decrease in variability for the VBSA (below). The difference between MFCs $1 / 3$ and MFC 2 was also observed when polarization curves were calculated from each pipet MFC (Fig. 2B). The average open circuit voltages and short circuit currents were $0.65 \pm 0.05 \mathrm{~V}$ and $0.021 \pm 0.003 \mathrm{~mA}$ (Fig. $2 \mathrm{~B}$ inset) from each MFC, respectively. The average power density from S. oneidensis DSP10 in all three MFCs was $4,400 \pm 500 \mathrm{~W} / \mathrm{m}^{3}$ (per volume) and $0.20 \pm 0.02 \mathrm{~mW} / \mathrm{m}^{2}$ (per cross-sectional electrode surface area).
A

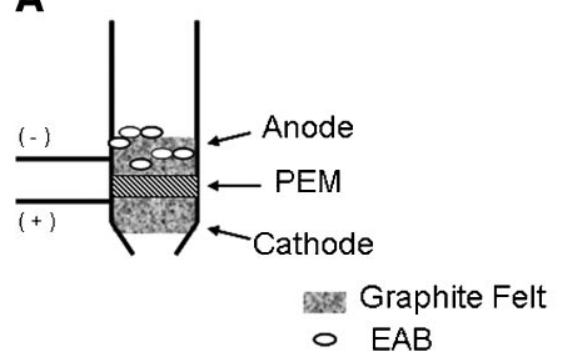

B

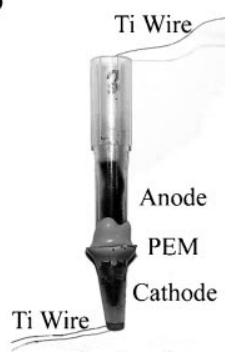

Figure 1. Images of the pipet MFC: (A) Schematic, (B) operating pipet MFC with titanium wires.
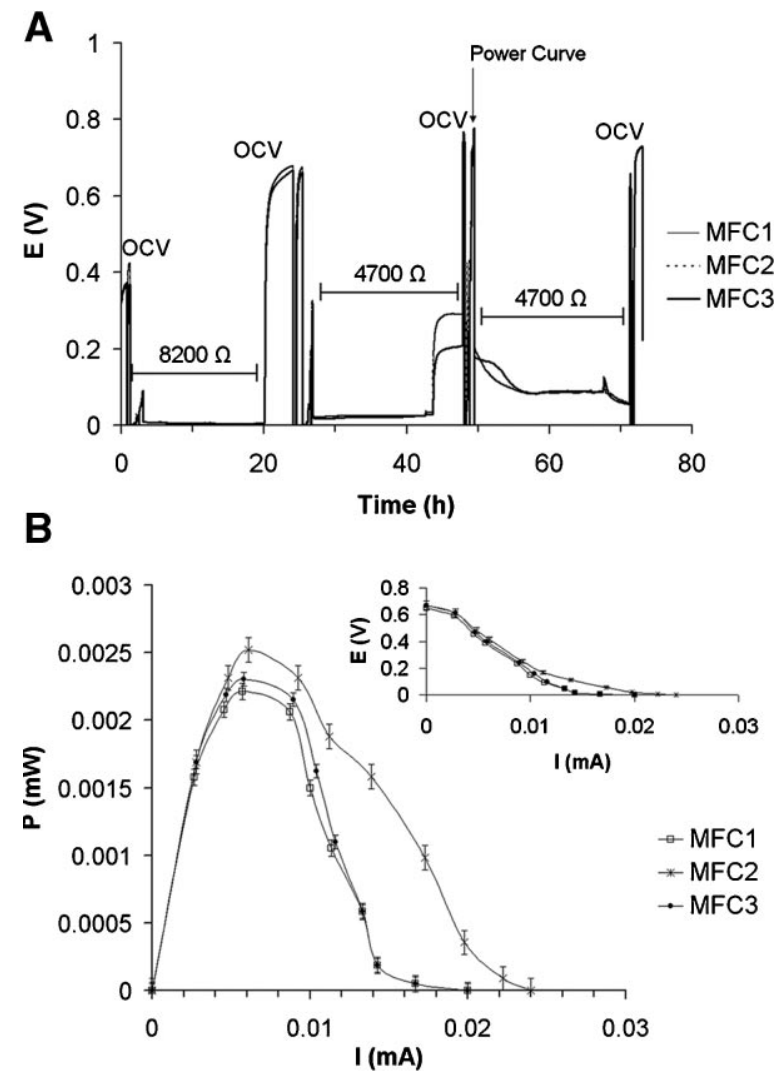

Figure 2. A: Time-voltage curves of three pipet MFCs containing $S$. oneidensis MR-1 with connected cathodes and (B) power and voltage (inset) versus current for individual pipet MFCs.

The power density (per surface area) of the pipet MFCs are considerably less than previously published MFCs. The best comparison of power density is with a miniature MFC (mini-MFC) (Ringeisen et al. 2006) because it was designed to maximize the surface area of the electrode to volume of the chamber similar to the pipet MFC. Due to small anode volume $(500 \mu \mathrm{L})$ and the minimization of void volume (GF filled fuel cell chambers), these pipet MFCs were able to be operated with air exposed anodes. Power from aerobic cultures was also observed using the mini-MFC (Ringeisen et al., 2007). The pipet MFC (as well as any MFC utilizing ferricyanide catholytes) could also be operated under anaerobic atmospheres because the redox couple for ferricyanide is not oxygen dependent. The percent deviation of all three pipet MFCs was $8 \%$ from the mean voltage recorded. This initial pipet design highlights the concept that power generation can be monitored in multiple biological air exposed anodes using a single cathode with a well-defined redox active catholyte.

\section{General VBSA Design and Properties}

The experimental design of pipet MFCs was used to fabricate an improved single frame batch reactor with a common 
A

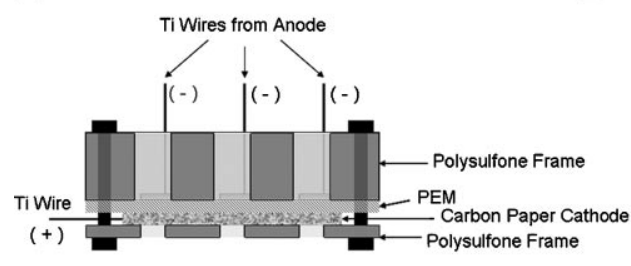

B

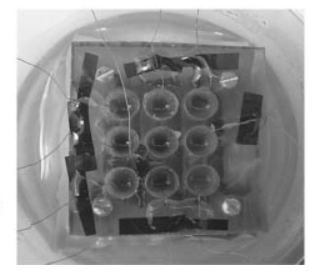

C

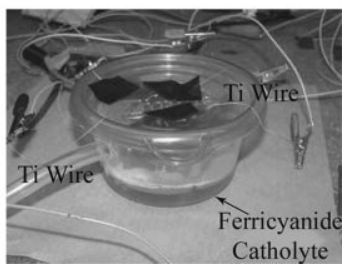

Figure 3. Images of the nine-well VBSA: (A) Schematic, (B) operating VSBA, and (C) device container with electrical connections.

cathode (Fig. 3). The total Ohmic resistance of an MFC can be quite pronounced considering the optimal operating conditions $\left(\mathrm{pH} 1,60^{\circ} \mathrm{C}\right)$ for Nafion membranes (Harnisch et al., 2008; Rozendal et al., 2006; Zhao et al., 2006) are not used in these systems. Voltage data collected from a fourwell VBSA containing $S$. oneidensis DSP10 inoculated with lactate was used to calculate the total Ohmic resistance $\left(R_{\Omega}\right.$, Eq. 1) of the system via the current-interrupt method (Cooper and Smith, 2006). The initial change in voltage $(\Delta E)(0.0112$, Fig. 4 inset) after operating the VBSA at $4 \mu \mathrm{A}$ (I) resulted in a $R_{\Omega}$ of $2,800 \pm 100 \Omega$. This high resistance was most likely due to the low power output and the high resistive state of the

$$
R_{\Omega}=\frac{\Delta E}{I}
$$

Nafion MEA initially. However, the total Ohmic resistance decreased considerably after 25 h of operation $(1,100 \pm 50$ $\Omega$ ). This was a common property with this prototype and resulted in a mandatory $10-25 \mathrm{~h}$ conditioning period for consistent results to be obtained from the VBSA. Conditioning the VBSA was accomplished by soaking each

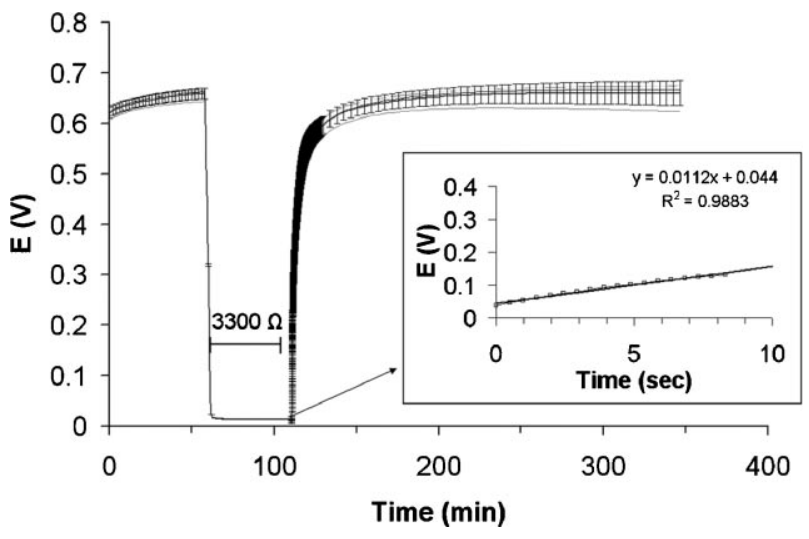

Figure 4. Parallel current-interrupt data for a 4-well VBSA containing $S$. oneidensis MR-1. Inset: Linear fit of voltage versus time data for total Ohmic resistance calculation. anode chamber with either sterile water or the medium of interest. Variation derived from the VBSA itself are mitigated by recording data against a control experiment run in parallel with the experiments of interest. The percent deviation between each of the wells $(5 \%)$ was determined from deviations in the mean voltage recorded throughout triplicate current-interrupt data sets (Fig. 4).

\section{Growth of S. oneidensis MR-1 and DSP10 Using the VBSA}

A variety of analytical methods (bioluminescence, immunology, microscopy, flow cytometry, electrochemical) are currently being employed to monitor the safety and quality of food and agricultural products from bacterial contaminants. There are few rapid and sensitive methods to monitor bacterial load and activity with most direct assays relying on oxygen respiration activity which is often inaccurate for anaerobic bacteria (Kuznetsov et al., 2004). A recently published assay for the rapid analysis of bacterial growth and metabolic activity used external mediators with integrated electrochemical methods for Mycobacterium smegmatis (Kuznetsov et al., 2006). Their system consisted of a standard three-electrode cell with working, reference, and platinum counter electrodes. The VBSA could also be used to monitor bacterial activity similar to the three electrode electrochemical systems by utilizing voltage changes with or without external mediators depending on the bacterial species. Standard three electrode systems will eventually be susceptible to biofouling of the reference and counter electrode considering they are both placed in the bacterial culture. The VBSA is designed with a universal ferricyanide cathode system separated from the bacterial culture by a Nafion ${ }^{\mathbb{R}}-117$ membrane making any changes in the cathode potential capable of being monitored independently by an additional reference electrode (example: $\mathrm{Ag} / \mathrm{AgCl}$ ), if necessary, and isolated from the bacteria of interest.

The growth of $S$. oneidensis MR-1 and DSP10 was examined with the VBSA using both open circuit voltage (OCV) (Fig. 5A) and current (Fig. 5B) at pH 7. A six-well VBSA was assembled with $300 \mu \mathrm{L}$ cell-free LB media in each anode chamber. After the initial conditioning period ( $25 \mathrm{~h}$ ), 

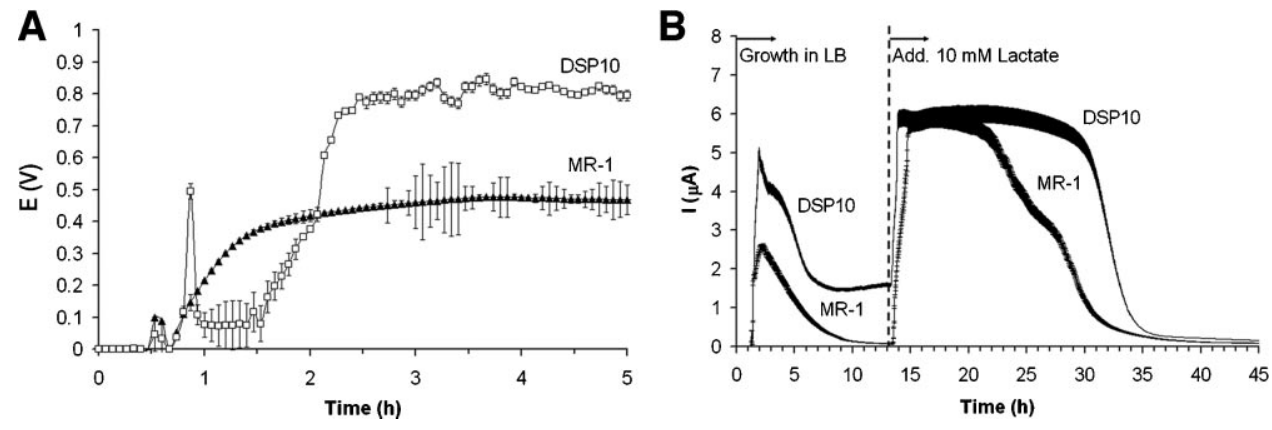

Figure 5. Time versus (A) open circuit voltage or (B) current curves generated from the growth of S. oneidensis DSP10 and MR-1 using the VBSA.

$100 \mu \mathrm{L}$ inocula from $1 \times 10^{8} \mathrm{CFU} / \mathrm{mL}$ MR- 1 and DSP10 cultures were added to each well. The voltage data collected from each chamber was substracted from a control experiment containing acellular LB. This data correction was necessary considering the presence of background voltage changes due to LB and carbon electrodes.

The data obtained at OCV would be the most rapid way to analyze the growth of Shewanella considering once the maximum potential difference is obtained, general activity could be monitored by a change in the OCV. There were large differences observed between the growth rates calculated using the VBSA with OCV and standard growth experiments (e.g., serial dilution or optical density). Typical OCVs reported in the literature for MFCs using a ferricyanide catholyte and Shewanella $(500-800 \mathrm{mV})$ were observed approximately $1 \mathrm{~h}$ after the MR-1 culture was added and (after a $1.2 \mathrm{~h}$ lag period) $1 \mathrm{~h}$ after the addition of DSP10 (Fig. 5A). Typical doubling times (calculated during exponential growth) for $S$. oneidensis range from 35 to 45 min under comparable conditions to those used for the VBSA (Abboud et al., 2005; Biffinger et al., 2008b). Doubling times calculated from the OCV data are $12 \mathrm{~min}$ for DSP 10 and $18 \mathrm{~min}$ for MR-1. These data suggest OCV is a poor indicator for bacterial growth. The growth curves generated using OCV are more likely showing the bacterial conditioning (biofilm formation, biosynthesis of redox mediators) of the electrode considering OCV is a measure of the maximum working potentials between the anode and cathode. Since there are no literature precedents for the rate bacteria condition an electrode, this metric should be useful in screening new electrode materials and coatings.

Large changes in OCV can be useful for qualitative measurements of the bacterial culture properties and electrode interactions, but OCV does not correlate to actual bacterial growth. If an external resistor is placed in series with each anode in the VBSA and connected to the universal cathode then each well will behave as individual MFCs. A second set of experiments were designed to relate current output directly with $S$. oneidensis growth in the presence of AQDS. An external mediator was added to eliminate current responses due to biofilm formation and bacterial conditioning of the electrode surface. The doubling times calculated for DSP 10 and MR-1 during the first $10 \mathrm{~h}$ of data in Figure 5B are 34 and 42 min, respectively. These doubling times were calculated using the initial slope from the current increase after the addition of bacteria to each anode well and are consistent with literature values (above). The data collected after the rise in current shows a gradual decrease in current to a steady state $10 \mathrm{~h}$ after the initial addition. Since current is being collected from these fuel cells, the gradual decrease in current is in response to a decrease in viable carbon sources for Shewanella. This gradual drop in current after $10 \mathrm{~h}$ is nothing like the OCV data (Fig. 5A) that showed no decrease in voltage until $25 \mathrm{~h}$ after the addition of bacteria (data not shown). The actual currents that were generated by MR-1 and DSP 10 can be deceiving considering that both strains utilize LB in dissimilar ways for current output. However, both strains utilize lactate the same and this was reflected in the identical maximum current output observed from DSP10 and MR-1 in Figure 5B when lactate was used as the sole carbon source.

Several properties of EAB can be observed by using the VBSA with OCV or current detection. These data suggest that OCV is a better metric for bacterial conditioning of electrodes and surfaces and not for bacterial growth. Conversely, current appears to be the best detection metric for bacterial growth rates. The use of external mediators is optional for screening $\mathrm{EAB}$, but should be used when the effects of bacterial conditioning and biofilm formation are to be negated.

\section{Screening for Carbon Substrate Utilization by Air Exposed S. oneidensis MR-1}

The VBSA will be useful for both applied and basic research applications involving biological electrochemically active species. Our interest in MFCs and Shewanella led us to screen a variety of potential electron donors for current output. Until recently, only a small number of organic electron donors (lactate, formate, pyruvate, amino acids, hydrogen) have supported metal reduction and power output from MFCs using $S$. oneidensis MR-1 under anaerobic atmospheres (Nealson et al., 2002). However, 
electron donors (such as glucose) that were thought to be unusable for power output by Shewanella have generated substantial power under an air exposed atmosphere using a miniature MFC (Biffinger et al., 2008a). Therefore, the effects of oxygen exposure on S. oneidensis MR-1 were tested with the VBSA prototype with various electron donors of interest (agar, sucrose, starch, glucose, fructose, lactate, acetate, citrate) using current detection. A $100 \mathrm{k} \Omega$ resistor was put in series with each anode well and connected to the universal cathode to generate a current. The use of an
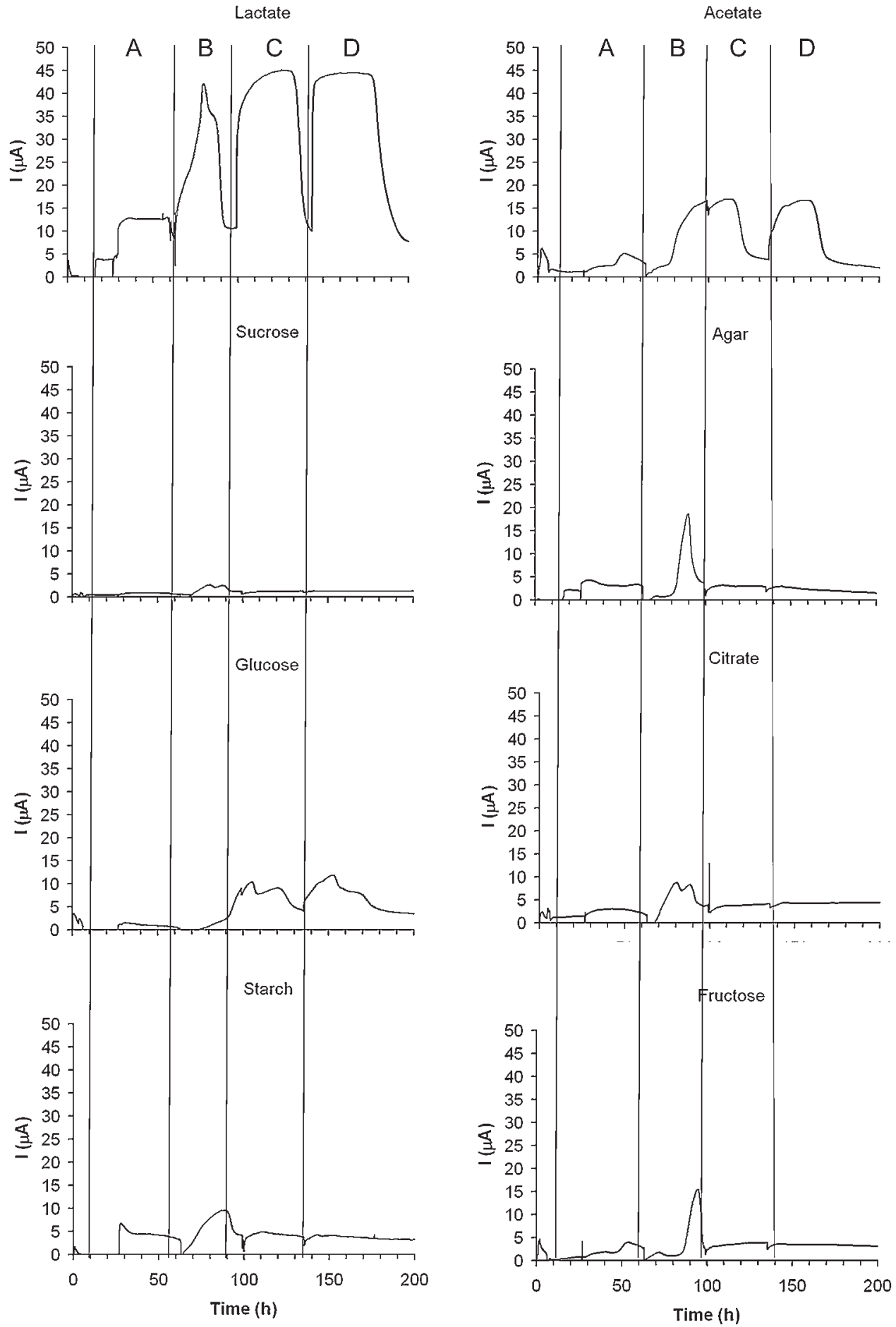

Figure 6. Current generated from air exposed anodes containing $S$. oneidensis MR-1 with selected electron donors in a nine-well VBSA. Sections A-D indic ate when electron donor was added. 
unusually high resistor will allow for comparisons to be made between EAB that produce both low and high currents, but will not optimize power output.

There were four distinct time periods defined during the operation of the VBSA (Fig. 6). Each period was defined by the addition of the carbon source to a concentration of $8 \mathrm{mM}$ in each well. Each anode well contained sterile water plus the electron donor for the first $10 \mathrm{~h}$ to condition the VBSA. At the beginning of time period A (Fig. 6), $1 \times 10^{8} \mathrm{CFU} / \mathrm{mL}$ S. oneidensis MR-1 cultures in $\mathrm{pH} 7 \mathrm{LB}$ replaced the sterile water with $1 \mathrm{mM}$ electron donor. The control experiment contained the original S. oneidensis MR-1 culture in LB and these data were used to standardize results between chambers. The largest current output was generated by lactate $(45 \mu \mathrm{A})$ over the next 35 h during time period ( $C$ and $\mathrm{D})$. Lactate produced comparable current after all additions following time period $\mathrm{B}$. This suggests that bacterial conditioning of the electrode was completed after $100 \mathrm{~h}$ of operation.

Of the remaining electron donors, only glucose and acetate generated consistent current responses from MR-1. These currents were significantly less than the $45 \mu \mathrm{A}$ generated by lactate $(\sim 10 \mu \mathrm{A})$ but definite positive current output was observed upon addition of glucose and acetate. Starch, agar, citrate, sucrose, and fructose did not show any significant response upon addition of each electron donor. The minor decreases in current at the beginning of each time period are from exposure to oxygen at the electrode during the mixing of the electron donor and the anolyte. During time period B, MR-1 exposed to starch, agar, sucrose, fructose, and citrate show significant increases in current but no comparable response from subsequent additions. These isolated responses suggest that all of the usable electron donors were exhausted resulting in either increased biofilm formation on the electrode (due to nutrient limited conditions) or a cell death response with the residual release of mediators and potential electron donors from cellular debris. Experiments are being performed currently to determine the factors that generate current spikes under carbon source limited conditions.

The results from this electron donor VBSA experiment show the complexity of bacterial metabolism and highlight the positive attributes of this prototype. Not only was a unique starvation behavior observed with respect to current output from starch, agar, citrate, sucrose, and fructose (response at the end of time period (B)), but lactate and acetate were confirmed as electron donors that could be utilized by MR-1 under oxygen exposure for current output from a MFC. In addition, glucose was identified as a potential electron donor, but only after acclimation of the air exposed anodes over several hours.

\section{Conclusions}

The VBSA is the first high throughput prototype using voltage and current output to monitor fundamental EAB properties as well as screen for potential electron donors in parallel for MFCs applications. The straightforward design for the VBSA makes it applicable for both microbial and enzymatic fuel cell engineering research. The use of a universal cathode and a well-defined catholyte (potassium ferricyanide) allows for small changes in voltage (and current) to be analyzed between each chamber with excellent reproducibility.

This work was funded by the Office of Naval Research (NRL 6.2 Program Element Number 62123N) and the Air Force Office of Scientific Research (MURI program, Award No. FA9550-06-10292). The authors would like to thank Barry Spargo for his helpful discussions about device design and fabrication methodology.

\section{References}

Abboud R, Popa R, Souza-Egipsy V, Giometti C, Tollaksen S, Mosher JJ, Findlay RH, Nealson KH. 2005. Low-temperature growth of Shewanella oneidensis MR-1. Appl Environ Microbiol 71(2):811-816.

Biffinger JC, Byrd JN, Dudley BL, Ringeisen BR. 2008a. Oxygen exposure promotes fuel diversity for Shewanella oneidensis microbial fuel cells. Biosens Bioelectron 23(6):820-826.

Biffinger JC, Pietron J, Bretschger O, Nadeau LJ, Johnson GR, Williams CC, Nealson KH, Ringeisen BR. 2008b. The influence of acidity on microbial fuel cells containing Shewanella oneidensis. Biosens Bioelectron, DOI: 10.1016/j.bios.2008.07.034

Bond DR, Holmes DE, Tender LM, Lovley DR. 2002. Electrode-reducing microorganisms that harvest energy from marine sediments. Science 295(5554):483-485.

Bretschger O, Obraztsova A, Sturm CA, Chang IS, Gorby YA, Reed SB, Culley DE, Reardon CL, Barua S, Romine MF, Zhou J, Beliaev AS, Bouhenni R, Saffarini D, Mansfeld F, Kim B-H, Fredrickson JK, Nealson KH. 2007. Current production and metal oxide reduction by Shewanella oneidensis MR-1 wild type and mutants. Appl Environ Microbiol 73(21):7003-7012.

Burbaum JJ, Sigal NH. 1997. New technologies for high-throughput screening. Curr Opin Chem Biol 1(1):72-78.

Burnes BS, Mulberry MJ, Dichristina TJ. 1998. Design and application of two rapid screening techniques for isolation of $\mathrm{Mn}(\mathrm{IV})$ reductiondeficient mutants of Shewanella putrefaciens. Appl Environ Microbiol 64(7):2716-2720.

Chang IS, Moon H, Bretschger O, Jang JK, Park HI, Nealson KH, Kim BH. 2006. Electrochemically active bacteria (EAB) and mediator-less microbial fuel cells. J Microbiol Biotechnol 16(2):163-177.

Cooper KR, Smith M. 2006. Electrical test methods for on-line fuel cell ohmic resistance measurements. J Power Sources 160:1088-1095.

Diaz-Mochon JJ, Tourniaire G, Bradley M. 2007. Microarray platforms for enzymatic and cell-based assays. Chem Soc Rev 36(3):449-457.

DiChristina TJ, Arnold RG, Lidstrom ME, Hoffmann MR. 1988. Dissimilative iron reduction by the marine eubacterium Alteromonas putrefaciens strain 200. Water Sci Technol 20(11-12):69-79.

Ganesh R, Robinson KG, Reed GD, Sayler GS. 1997. Reduction of hexavalent uranium from organic complexes by sulfate- and iron-reducing bacteria. Appl Environ Microbiol 63(11):4385-4391.

Harms P, Kostov Y, French JA, Soliman M, Anjanappa M, Ram A, Rao G. 2005. Design and performance of a 24-station high-throughput microbioreactor. Biotechnol Bioeng 93(1):6-13.

Harnisch F, Schröder U, Scholz F. 2008. The suitability of monopolar and bipolar ion exchange membranes as separators for biological fuel cells. Environ Sci Technol 42(5):1740-1746.

Inglese J, Johnson RL, Simeonov A, Xia M, Zheng W, Austin CP, Auld DS. 2007. High-throughput screening assays for the identification of chemical probes. Nat Chem Biol 3(8):466-479. 
Kim HJ, Hyun MS, Chang IS, Kim BH. 1999. A microbial fuel cell type lactate biosensor using a metal-reducing bacterium, Shewanella putrefaciens. J Microbiol Biotechnol 9(3):365-367.

Kim HJ, Park HS, Hyun MS, Chang IS, Kim M, Kim BH. 2002. A mediatorless microbial fuel cell using a metal reducing bacterium, Shewanella putrefaciens. Enzyme Microb Technol 30(2):145-152.

Kuznetsov BA, Davydova ME, Shleeva MO, Shleev SV, Kaprelyants AS, Yaropolov AI. 2004. Electrochemical investigation of the dynamics of Mycobacterium smegmatis cells transformation to dormant, nonculturable form. Bioelectrochemistry 64(2):125-131.

Kuznetsov BA, Khlupova MT, Shleev SV, Kaprel'yants AS, Yaropolov AI. 2006. An electrochemical method for measuring metabolic activity and counting cells. Appl Biochem Microbiol 42(5):525-533.

Logan BE, Regan JM. 2006. Microbial fuel cells-Challenges and applications. Environ Sci Technol 40(17):5172-5180.

Lovley DR, Coates JD. 1997. Bioremediation of metal contamination. Curr Opin Biotechnol 8(3):285-289.

Lovley DR, Phillips EJP. 1987. Rapid assay for microbially reducible ferric iron in aquatic sediments. Appl Environ Microbiol 53(7):15361540 .

Lovley DR, Phillips EJP. 1988. Novel mode of microbial energy metabolism: Organic carbon oxidation coupled to dissimilatory reduction of iron or manganese. Appl Environ Microbiol 54(6):1472-1480.

Lovley DR, Coates JD, Saffarini DA, Lonergan DJ. 1997. Dissimilatory iron reduction. In: Winklemann G, Carrano CJ, editors. Transition metals in microbial metabolism. Amsterdam, The Netherlands: Harwood. p 187215.

Maharbiz MM, Holtz WJ, Howe RT, Keasling JD. 2004. Microbioreactor arrays with parametric control for high-throughput experimentation. Biotechnol Bioeng 85(4):376-381.

Myers CR, Nealson KH. 1988. Bacterial manganese reduction and growth with manganese oxide as the sole electron acceptor. Science 240(4857): 1319-1321.

Nealson KH, Belz A, McKee B. 2002. Breathing metals as a way of life: Geobiology in action. Antonie van Leeuwenhoek 81(1-4):215-222.

Payne AN, DiChristina TJ. 2006. A rapid mutant screening technique for detection of technetium [Tc(VII)] reduction-deficient mutants of Shewanella oneidensis MR-1. FEMS Microbiol Lett 259(2):282287.

Richter H, Lanthier M, Nevin KP, Lovley DR. 2007. Lack of electricity production by Pelobacter carbinolicus indicates that the capacity for $\mathrm{Fe}(\mathrm{III})$ oxide reduction does not necessarily confer electron transfer ability to fuel cell anodes. Appl Environ Microbiol 73(16):5347-5353.

Ringeisen BR, Henderson E, Wu PK, Pietron J, Ray R, Little B, Biffinger JC, Jones-Meehan JM. 2006. High power density from a miniature microbial fuel cell using Shewanella oneidensis DSP10. Environ Sci Technol 40(8):2629-2634.

Ringeisen BR, Ray R, Little B. 2007. A miniature microbial fuel cell operating with an aerobic anode chamber. J Power Sources 165(2): 591-597.

Rozendal RA, Hamelers HVM, Buisman CJN. 2006. Effects of membrane cation transport on $\mathrm{pH}$ and microbial fuel cell performance. Environ Sci Technol 40(17):5206-5211.

Smotkin ES, Jiang J, Nayar A, Liu R. 2006. High-throughput screening of fuel cell electrocatalysts. Appl Surf Sci 252:2573-2579.

Stams AJM, de Bok FAM, Plugge CM, van Eekert MHA, Dolfing J, Schraa G. 2006. Exocellular electron transfer in anaerobic microbial communities. Environ Microbiol 8(3):371-382.

Storz G, Hengge-Aronis R, editors. 2000. Bacterial stress responses. Washington, DC: ASM Press. 485 p.

Sundberg SA. 2000. High-throughput and ultra-high-throughput screening: Solution- and cell-based approaches. Curr Opin Biotechnol 11(1):47-53.

Tang YJ, Laidlaw D, Gani K, Keasling JD. 2006. Evaluation of the effects of various culture conditions on $\mathrm{Cr}(\mathrm{VI})$ reduction by Shewanella oneidensis MR-1 in a novel high-throughput mini-bioreactor. Biotechnol Bioeng 95(1):176-184.

Taratus EM, Eubanks SG, DiChristina TJ. 2000. Design and application of a rapid screening technique for isolation of selenite reductiondeficient mutants of Shewanella putrefaciens. Microbiol Res 155(2): 79-85.

Zhao F, Harnisch F, Schröder U, Scholz F, Bogdanoff P, Herrmann I. 2006. Challenges and constraints of using oxygen cathodes in microbial fuel cells. Environ Sci Technol 40(17):5193-5199. 